\title{
Physical Fitness and Anthropometric Characteristics in Different Levels of Young Team Handball Players
}

\author{
Ilias Zapartidis*, Ioannis Vareltzis, Marina Gouvali and Panagiotis Kororos
}

National and Kapodistrian University of Athens, Department of Physical Education \& Sports Science

\begin{abstract}
The aim of the study was to compare physical fitness and selected anthropometric characteristics between selected (SP) and non-selected (NSP) for the Greek preliminary national team male $(n=88)$ and female $(n=73)$ young handball players. Results revealed that compared to NSP players, male SP players presented higher values in ball velocity $(\mathrm{p}=.001)$ standing long jump ( $\mathrm{p}=.016), 30-\mathrm{m}$ sprint $(\mathrm{p}=.034)$ and estimated $\mathrm{VO}_{2 \max }(\mathrm{p}=.018)$, while female SP players presented higher values only in ball velocity $(\mathrm{p}=.009)$ and standing long jump $(\mathrm{p}=.045)$. Male SP players were taller $(\mathrm{p}=.042)$ and had larger arm span ( $\mathrm{p}=.031)$. Taking into account the different playing positions, significant differences (in favor of SP) were found between SP and NSP male backs in stature $(p=.008)$, hand spread $(p=.042)$, arm span $(p=.019)$ and ball velocity $(\mathrm{p}=.005)$. Female SP revealed higher values in stature $(\mathrm{p}=.041)$ and arm span $(\mathrm{p}=.046)$. For wings, significant differences were found in ball velocity $(\mathrm{p}=.007), 30-\mathrm{m}$ sprint $(\mathrm{p}=.039)$ and estimated $\mathrm{VO}_{2 \max }(\mathrm{p}=.002)$ between SP and NSP male players (in favor of SP) and in estimated $\mathrm{VO}_{2 \max }(\mathrm{p}=.019)$ between SP and NSP female players. For pivots, significant differences were found only in ball velocity $(\mathrm{p}=.001)$ between SP and NSP females (in favor of SP). Finally, no statistically significant differences were found between SP and NSP male and female goalkeepers. Current results suggest that physical and anthropometric characteristics should be included in any testing procedure of junior handball players.
\end{abstract}

\section{INTRODUCTION}

Team handball is a complex intermittent game, which requires players to have well developed aerobic and anaerobic capacities [1]. Motor ability, sprinting, jumping, flexibility and throwing velocity represent physical activities that are considered as important aspects of the game and contribute to the high performance of the team. Successful performance requires explosive power of the legs and arms, sprint velocity and kinesthetic feeling in ball control [2]. On the other hand, for a modern model of a handball player, the pronounced longitudinal dimensions such as stature, arm span, hand spread and length are necessary [2-4]. Such an anthropometric profile plays a supportive role in helping athletes perform under actual competitive conditions [3]. Longer upper extremities contribute to maximizing throwing velocity [5] and longer hand spread and length influence specific motor abilities such as dribble, passing, catching and ball throwing [4]. Concerning functional and fitness properties, high level male and female adult players develop maximal oxygen uptake between $55-60 \mathrm{ml} \cdot \mathrm{kg}^{-1} \cdot \mathrm{min}^{-1}$ and $46-55$ $\mathrm{ml} \cdot \mathrm{kg}^{-1} \cdot \mathrm{min}^{-1}, 30-\mathrm{m}$ sprint between 3.8-4.4 $\mathrm{sec}$ and 4.4-5.5 $\mathrm{sec}$ and standing long jump between $280-300 \mathrm{~cm}$ and 165 $230 \mathrm{~cm}$ respectively [6-8]. At last, the throwing velocity from a standing position for international level handball players ranges between 20-24 $\mathrm{m} \cdot \mathrm{sec}^{-1}$ and $16-23 \mathrm{~m} \cdot \mathrm{sec}^{-1}$ [8-10].

Besides the importance of physical fitness features of young handball players, those are poorly evaluated. From the relevant literature it seems that there is little information available concerning the motor abilities and specific

*Address correspondence to this author at the National and Kapodistrian University of Athens, Department of Physical Education \& Sports Science; E-mail: elzapa@phed.uoa.gr anthropometric characteristics of young handball players. In addition, studies reporting differences in the above characteristics between elite and sub-elite young players are rather rare. In a recent study, significant differences between elite and sub-elite junior male players were found in standing long jump and 20-m sprint, whilst for female players only in standing long jump. In all other motor abilities, a wide overlap has been reported between elite and sub-elite players [11].

Investigating the profile of young handball players, we can define the characteristics that contribute to a player's selection for the team. In addition, results from motor performance tests will allow trainers to identify players' weaknesses and design training models for improving specific athletes' deficiencies, but also follow up the athlete's improvement during a competitive season. Furthermore, the data of the present study could be added in the international literature and assist in talent identification and development. The aim of the present study was a) to define the anthropometric and physical fitness characteristics of youth male and female handball players and b) to determine the differences in physical fitness and selected anthropometric characteristics between selected (SP) and non-selected (NSP) for the preliminary national team young handball players. We assume that the SP players (male and female) compared to NSP, will surpass them in terms of anthropometric and physical fitness characteristics.

\section{METHODS}

\section{Subjects}

The total sample consisted of 161 male $(n=88)$ and female $(n=73)$ young handball players. All players participated at the highest league according to their age category. In addi- 
tion all players were invited to train in youth pro-selection groups. Both players and their parents were informed about the procedures of the measurements including the risks and benefits and provided their written consent for participating according to the research policy of the University of Athens.

After the measurements, players were selected (SP) into a preliminary national team based on the opinions of 7 national trainers during a small overall tournament. The players, who were not selected into the preliminary national team, formed the non-selected sample (NSP). The data which were measured at this study were not used in the selection process. At this level the position specialization begins, so male and female athletes were also clustered according to their position in the team (backs: 46 male, 31 female, wings: 20 male, 22 female, pivots: 12 male, 9 female and goalkeepers, 10 male, 11 female).

\section{Anthropometric Characteristics}

Six variables were measured for each subject: Stature, body mass, body mass index (BMI), arm span, hand spread and length. The specific features were selected because they influence motor abilities (passing, catching and ball throwing) and help athletes' performance [2-5]. All length characteristics were measured to the nearest $0.1 \mathrm{~cm}$ and mass characteristics were measured in $\mathrm{kg}$. All measurements were taken by the same investigator. BMI was computed as the ratio of body mass to the squared standing stature $\left(\mathrm{Kg} \cdot \mathrm{m}^{-2}\right)$.

\section{Physical Characteristics}

Five variables were recorded for each player. These included aerobic capacity, explosive power of the lower limbs, ball velocity, flexibility and running speed.

Aerobic capacity was expressed as estimated maximal oxygen uptake $\left(\mathrm{VO}_{2 \max }\right)$ using a $20-\mathrm{m}$ shuttle run test and predicted by a regression equation according to the age and the running speed at the last completed stage [12].

Standing long jump was used for assessing the explosive power of the lower limbs by instructing players to stand behind a line and jump as far as possible - allowing arms and legs countermovement.

Ball velocity was measured by a radar gun (Sport Electronics, USA). The height of the gun radar was adjusted individually according to the athlete's throwing arm height. The contra-lateral leg of the throwing hand was placed to the front and steadily on the ground (penalty throw).

In order to compute lower back and hamstring flexibility, players were measured with the sit and reach test to the nearest $0.1 \mathrm{~cm}$. Players were instructed to sit with straight legs and perform a maximal trunk flexion, aiming to reach as far forward as possible. A $90^{\circ}$ angle was kept for ankles, while value " 0 " was set at the position of just reaching the toes.

Running speed test included a 30-m sprint from a standing position. Times were recorded using electronic photocells (Brower timing system, USA). Players had to run for a distance of $30 \mathrm{~m}$ as fast as they could.

Except 20-m shuttle run test, all other tests were performed twice from which the best was selected for analysis.

\section{Statistical Analysis}

Descriptive data (mean and standard deviation) were computed for all variables. Independent t-tests were applied for testing significant differences between SP and NSP. Furthermore, t-tests between categories (SP-NSP) were also contacted separately for each playing position. Data for males and females were also analyzed separately. Statistical significance was set at $5 \%$.

\section{Results}

Physical fitness and anthropometric characteristics of the whole sample are presented in Table $\mathbf{1}$. Statistically significant differences were found between SP and NSP male players in stature $(\mathrm{p}=.042)$, arm span $(\mathrm{p}=.031)$, ball velocity $(\mathrm{p}=.001)$, standing long jump ( $\mathrm{p}=.016), 30$-m sprint $(\mathrm{p}=.034)$ and in the estimated $\mathrm{VO}_{2 \max }(\mathrm{p}=.018)$, and between $\mathrm{SP}$ and NSP female players in ball velocity $(\mathrm{p}=.009)$ and standing long jump $(\mathrm{p}=.045)$ (Table 2). No significant differences were found in weight, ratio arm span/stature, hand length and spread, and sit-and-reach flexibility. Considering the different playing positions, significant differences were found between SP and NSP male backs in stature $(\mathrm{p}=.008)$, hand spread $(\mathrm{p}=.042)$, arm span $(\mathrm{p}=.019)$ and ball velocity $(\mathrm{p}=.005)$. For the female sample on the other hand in stature $(\mathrm{p}=.041)$ and arm span $(\mathrm{p}=.046)$ (Table 3). For wings, significant differences were found in ball velocity $(p=.007), 30$ $\mathrm{m}$ sprint $(\mathrm{p}=.039)$ and estimated $\mathrm{VO}_{2 \max }(\mathrm{p}=.002)$ between SP and NSP male players and in estimated $\mathrm{VO}_{2 \max }(\mathrm{p}=.019)$ between SP and NSP female players (Table 4). For pivots, significant differences were found only in ball velocity $(\mathrm{p}=.001)$ between SP and NSP females (Table 5). Finally, no statistically significant differences were found between SP and NSP male and female goalkeepers (Table 6).

Table 1. Anthropometric and Physical Characteristics of Male and Female Young Handball Players (Mean \pm sd)

\begin{tabular}{|c|c|c|}
\hline Variable & Male $(n=88)$ & Female $(n=73)$ \\
\hline Age & $14.05 \pm 0.35$ & $13.68 \pm 0.53$ \\
\hline Stature $(\mathrm{cm})$ & $174.45 \pm 6.35$ & $164.31 \pm 6.35$ \\
\hline Weight $(\mathrm{Kg})$ & $69.68 \pm 11.77$ & $57.06 \pm 8.75$ \\
\hline $\mathrm{BMI}\left(\mathrm{Kg} \cdot \mathrm{m}^{-2}\right)$ & $22.96 \pm 3.41$ & $21.10 \pm 2.71$ \\
\hline Hand Length $(\mathrm{cm})$ & $19.24 \pm 0.84$ & 17.740 .89 \\
\hline Hand Spread (cm) & $22.97 \pm 1.48$ & $20.79 \pm 1.19$ \\
\hline Arm Span (cm) & $179.29 \pm 7.33$ & $166.60 \pm 8.32$ \\
\hline Standing long jump $(\mathrm{cm})$ & $201.46 \pm 23.49$ & $177.86 \pm 20.39$ \\
\hline 30-m speed (s) & $4.81 \pm 0.27$ & $5.19 \pm 0.24$ \\
\hline Sit-and-reach $(\mathrm{cm})$ & 33.037 .76 & $37.45 \pm 7.37$ \\
\hline Ball Velocity $\left(\mathrm{Km} \cdot \mathrm{h}^{-1}\right)$ & $70.72 \pm 7.00$ & $59.01 \pm 6.17$ \\
\hline $\mathrm{VO}_{2 \max }\left(\mathrm{ml} \cdot \mathrm{kg}^{-1} \cdot \mathrm{min}^{-1}\right)$ & $50.41 \pm 4.60$ & $47.34 \pm 4.26$ \\
\hline
\end{tabular}


Table 2. Differences in Anthropometric and Physical Characteristics of Male and Female SP and NSP (Mean \pm sd)

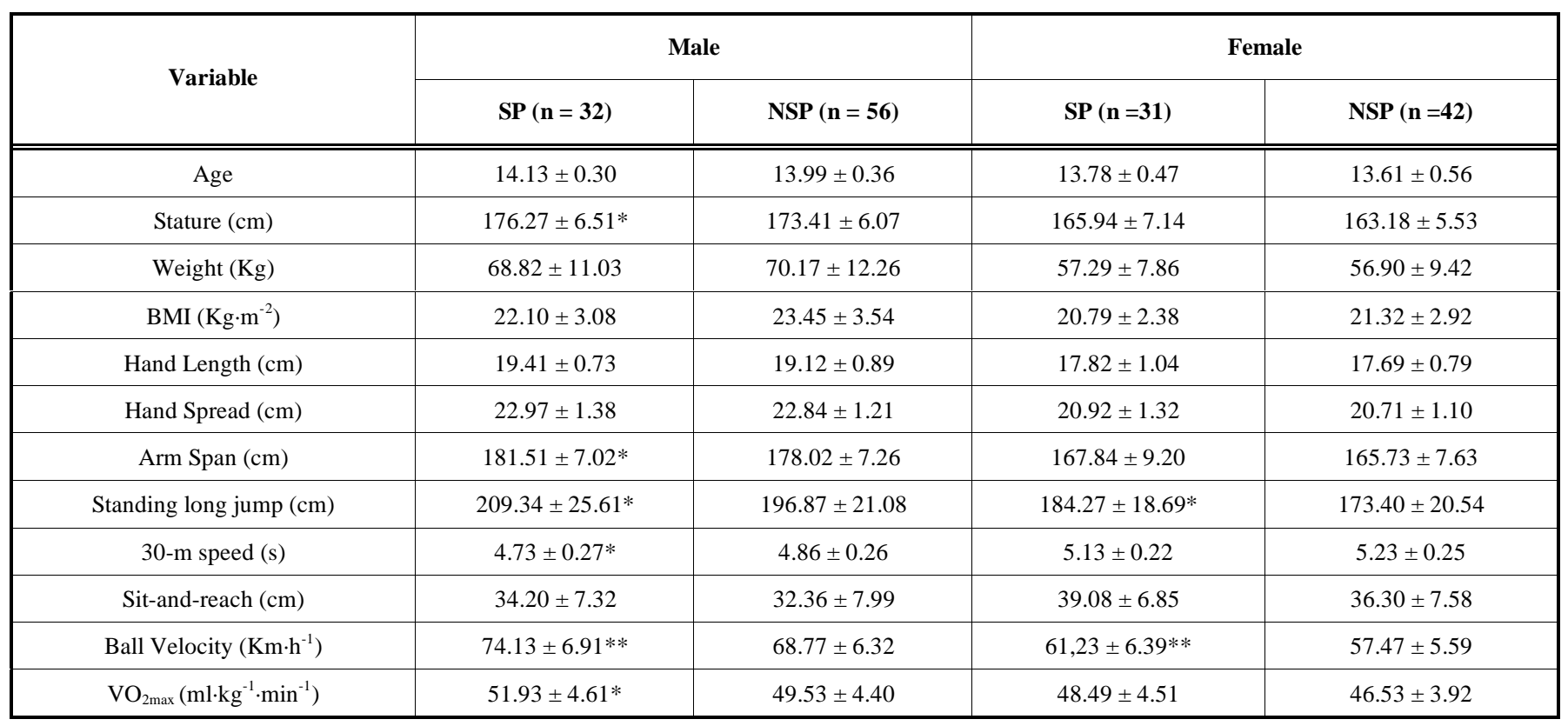

*Significantly different from NSP (p<.05). ** Significantly different from NSP ( $<<.01)$.

Table 3. Differences in Anthropometric and Physical Characteristics Between Male and Female SP and NSP Backs (Mean \pm sd)

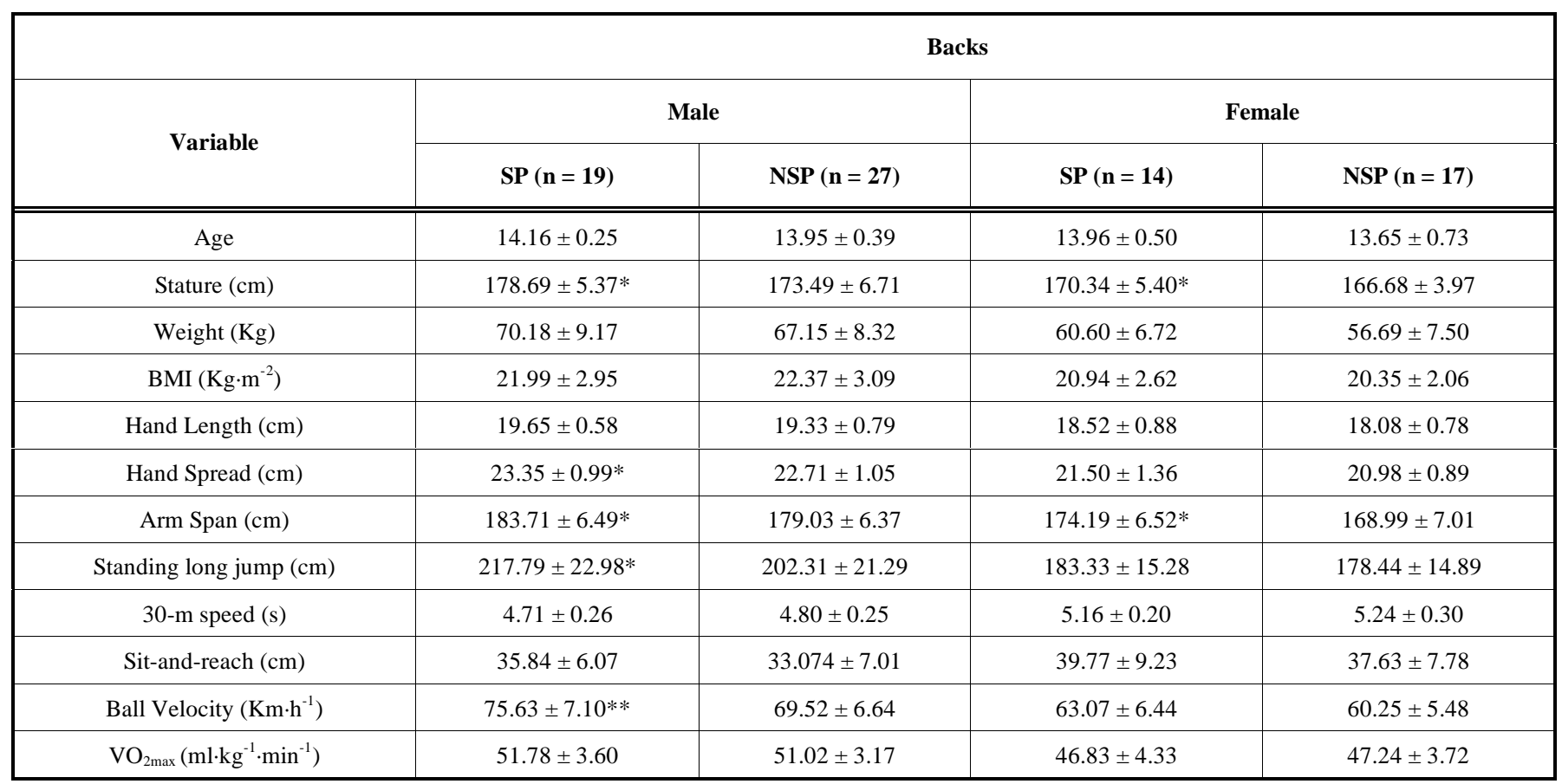

*Significantly different from NSP $(\mathrm{p}<.05)$. ** Significantly different from NSP $(\mathrm{p}<.01)$.

\section{DISCUSSION}

The aim of the present study was to determine the differences in physical fitness and specific anthropometric characteristics between SP and NSP young handball players. The scarcity of literature data concerning anthropometric and physical fitness characteristics of elite young handball players compared to their sub-elite counterparts make the comparison of the current results difficult.

\section{Anthropometric Characteristics}

SP and NSP male and female players were taller and heavier and presented wider span than those reported in other studies $[11,13]$. Moreover, the results of the present study show that stature and arm span differ significantly between SP and NSP players, this difference being in SP favour. This is more obvious in backs with significantly wider arm span $(183.71 \pm 6.49 \mathrm{~cm}$ vs $179.03 \pm 6.37 \mathrm{~cm}$ and $174.19 \pm 6.52 \mathrm{~cm}$ 
Table 4. Differences in Anthropometric and Physical Characteristics Between Male and Female SP and NSP Wings (Mean \pm sd)

\begin{tabular}{|c|c|c|c|c|}
\hline \multirow{2}{*}{ Variable } & \multicolumn{4}{|c|}{ Wings } \\
\hline & \multicolumn{2}{|c|}{ Male } & \multicolumn{2}{|c|}{ Female } \\
\hline Age & $14.07 \pm 0.44$ & $13.93 \pm 0.44$ & $13.61 \pm 0.43$ & $13.46 \pm 0.49$ \\
\hline Stature $(\mathrm{cm})$ & $174.64 \pm 5.35$ & $173.13 \pm 5.78$ & $158.66 \pm 3.72$ & $158.94 \pm 4.09$ \\
\hline $\mathrm{BMI}\left(\mathrm{Kg} \cdot \mathrm{m}^{-2}\right)$ & $20.48 \pm 2.06$ & $21.22 \pm 2.27$ & $19.76 \pm 1.17$ & $20.28 \pm 1.79$ \\
\hline Hand Length $(\mathrm{cm})$ & $19.16 \pm 0.41$ & $18.67 \pm 0.77$ & $16.95 \pm 0.76$ & $17.43 \pm 0.73$ \\
\hline Hand Spread $(\mathrm{cm})$ & $22.86 \pm 1.48$ & $22.73 \pm 1.05$ & $20.30 \pm 1.34$ & $20.84 \pm 1.17$ \\
\hline Arm Span $(\mathrm{cm})$ & $178.77 \pm 5.23$ & $173.67 \pm 4.88$ & $159.30 \pm 6.37$ & $161.01 \pm 6.99$ \\
\hline Standing long jump $(\mathrm{cm})$ & $206.43 \pm 17.42$ & $196.38 \pm 24.64$ & $182.80 \pm 19.74$ & $179.82 \pm 15.28$ \\
\hline $\mathrm{VO}_{2 \max }\left(\mathrm{ml} \cdot \mathrm{kg}^{-1} \cdot \mathrm{min}^{-1}\right)$ & $56.39 \pm 2.74 * *$ & $51.04 \pm 3.44$ & $51.83 \pm 3.42 *$ & $48.56 \pm 2.57$ \\
\hline
\end{tabular}

*Significantly different from NSP $(\mathrm{p}<.05)$. ** Significantly different from NSP $(\mathrm{p}<.01)$.

Table 5. Differences in Anthropometric and Physical Characteristics Among Elite and Sub-Elite Male and Female Pivots $($ Mean \pm sd $)$

\begin{tabular}{|c|c|c|c|c|}
\hline \multirow{2}{*}{ Variable } & \multicolumn{4}{|c|}{ Pivots } \\
\hline & \multicolumn{2}{|c|}{ Male } & \multicolumn{2}{|c|}{ Female } \\
\hline Age & $14.41 \pm 0.07$ & $14.14 \pm 0.15$ & $13.68 \pm 0.52$ & $13.87 \pm 0.40$ \\
\hline Stature $(\mathrm{cm})$ & $178.85 \pm .012$ & $174.61 \pm 6.60$ & $168.37 \pm 3.79$ & $160.92 \pm 4.98$ \\
\hline Hand Length $(\mathrm{cm})$ & $20.00 \pm 1.55$ & $19.51 \pm 1.08$ & $18.07 \pm 0.45^{*}$ & $17.08 \pm 0.50$ \\
\hline Hand Spread $(\mathrm{cm})$ & $25.10 \pm 0.28$ & $23.51 \pm 1.70$ & $21.23 \pm 0.55$ & $20.10 \pm 1.33$ \\
\hline Arm Span $(\mathrm{cm})$ & $183.73 \pm 13.08$ & $181.97 \pm 10.26$ & $170.83 \pm 5.01$ & $163.75 \pm 4.92$ \\
\hline Standing long jump (cm) & $195.50 \pm 26.16$ & $185.20 \pm 12.99$ & $169.67 \pm 17.10$ & $162.83 \pm 14.20$ \\
\hline $\mathrm{VO}_{2 \max }\left(\mathrm{ml} \cdot \mathrm{kg}^{-1} \cdot \mathrm{min}^{-1}\right)$ & $49.48 \pm 0.12$ & $45.87 \pm 5.42$ & $46.20 \pm 2.13$ & $44.13 \pm 3.81$ \\
\hline
\end{tabular}

*Significantly different from NSP $(\mathrm{p}<.05)$. ** Significantly different from NSP $(\mathrm{p}<.01)$.

vs $168.99 \pm 7.01 \mathrm{~cm}$ for SP and NSP male and female players respectively. These variables are very important in team handball and form a condition for higher performance [2, 4]. Back players are considerably the tallest in the team and they present larger body segments. They are responsible for organizing the team, they participate in defense aiming to block the opponents' shoots, they are specialized in distant shoots and they are efficient in shooting at the goal over the defensive wall [3]. The ratio arm span/stature for elite athletes should be 1.05-1.06 [4, 14]. Additionally, it has been reported that the players who throw the ball at a higher velocity seem to have a wider arm span related to their body height [4]. In our study, young players exhibited a ratio of 1.03 (males) and 1.01 (females) with no differences between SR and NSR players. Hand length and hand spread showed a non-significant higher level in favor of SP male and female players. These variables are important for ball control during the game and are correlated to throwing velocities [4]. Additionally, throwing velocity gradually increases as the hand length is increasing during the years of growth [4]. Values of the present study for young players are considered satisfactory, as the hand length should equal at least the ball diameter [15]. 
Table 6. Differences in Anthropometric and Physical Characteristics Among Elite and Sub-Elite Male and Female Goalkeepers $($ Mean \pm sd)

\begin{tabular}{|c|c|c|c|c|}
\hline \multirow{2}{*}{ Variable } & \multicolumn{4}{|c|}{ Goalkeepers } \\
\hline & \multicolumn{2}{|c|}{ Male } & \multicolumn{2}{|c|}{ Female } \\
\hline Age & $13.99 \pm 0.26$ & $14.08 \pm 0.18$ & $13.80 \pm 0.36$ & $13.47 \pm 0.28$ \\
\hline Stature $(\mathrm{cm})$ & $173.30 \pm 5.54$ & $172.63 \pm 3.60$ & $166.83 \pm 6.47$ & $163.53 \pm 6.92$ \\
\hline $\mathrm{BMI}\left(\mathrm{Kg} \cdot \mathrm{m}^{-2}\right)$ & $24.40 \pm 4.10$ & $24.35 \pm 2.66$ & $21.36 \pm 3.06$ & $24.74 \pm 3.97$ \\
\hline Hand Length (cm) & $18.70 \pm 0.71$ & $18.80 \pm 0.91$ & $17.45 \pm 0.48$ & $17.60 \pm 0.74$ \\
\hline Hand Spread $(\mathrm{cm})$ & $20.88 \pm 1.30$ & $22.68 \pm 1.33$ & $20.35 \pm 0.30$ & $20.24 \pm 1.25$ \\
\hline Arm Span (cm) & $179.45 \pm 6.01$ & $176.26 \pm 5.68$ & $164.28 \pm 6.19$ & $167.41 \pm 9.61$ \\
\hline Ball Velocity $\left(\mathrm{Km} \cdot \mathrm{h}^{-1}\right)$ & $66.00 \pm 3.74$ & $64.67 \pm 1.97$ & $57.50 \pm 4.51$ & $54.71 \pm 6.63$ \\
\hline $\mathrm{VO}_{2 \max }\left(\mathrm{ml} \cdot \mathrm{kg}^{-1} \cdot \min ^{-1}\right)$ & $46.05 \pm 5.47$ & $45.91 \pm 4.21$ & $46.04 \pm 4.66$ & $43.40 \pm 4.91$ \\
\hline
\end{tabular}

No significant differences were found between SP and NSP goalkeepers.

Mean values of BMI were not statistically different between SP and NSP, although both male and female SP players show a better index. In the present study BMI was 22.10 and $20.79 \mathrm{Kg} \cdot \mathrm{m}^{-2}$ for SP male and female players and 23.45 and $21.32 \mathrm{Kg} \cdot \mathrm{m}^{-2}$ for their NSP peers respectively. Only the BMI of NSP males was higher than values reported for handball players in previous research (range between 22.1$22.8 \mathrm{Kg} \cdot \mathrm{m}^{-2}$ ) [3, 16]. Regarding female players, recent studies report a BMI of $23.6 \mathrm{Kg} \cdot \mathrm{m}^{-2}$ for older players of the A1 and A2 national league of Greece [16].

Although anthropometric characteristics such as body stature, body mass, limb girths and bone circumferences provide as with interesting information, they are related to performance in a complicated way (see Williams \& Reilly) [17]. Moreover, the size of that correlation is being modified through different levels of maturation, as anthropometric characteristics are affected by heredity in different ways [18]. As a result, some anthropometric characteristics, such as body stature, can be unreliable predictors of a future performance potential because of their high variability during puberty [19]. Therefore, it is not safe to overestimate the anthropometric characteristics of junior players as predictors of their future anthropometric profile [17].

\section{Physical Fitness Characteristics}

Throwing ball velocity in team handball is a very important component contributing to the success of the game. In the present study, ball velocity was $70.72 \pm 7.00$ for males and $59.01 \pm 6.20 \mathrm{Km} \cdot \mathrm{h}^{-1}$ for females. It is difficult to compare the current results with other studies, as no data exist for ball velocity for similar ages. Mean ball velocity, as measured in this study for the male players, is less than velocity mentioned for children that are one year older $\left(71.7 \mathrm{Km} \cdot \mathrm{h}^{-1}\right)$ [20]. Additionally, mean ball velocity as measured for females in the present study is in accordance with the respective report for Greek 20yrs female players $\left(58-61 \mathrm{Km} \cdot \mathrm{h}^{-1}\right)$ [21].

One of the main findings of the present study was the difference in ball velocity between SP and NSP. SP are at a significantly higher level than the NSP regarding ball velocity. This is clearer for backs and wings, who are the players executing most of the shots at the goal. SP back and wings players show higher values by $9 \%$ in ball velocity compared to NSP. Differences in ball velocity have also been reported between first division and second division adult male players $\left(86.6 \mathrm{vs} 72.3 \mathrm{Km} \cdot \mathrm{h}^{-1}\right)$ [22] and between elite and amateur male and female players (85.7 vs 78.5 and 70.2 vs 62.6 $\mathrm{Km} \cdot \mathrm{h}^{-1}$ respectively) [8, 9]. The importance of ball velocity during a game, especially during the thrower's effort to beat opponents' defense and goalkeeper, is proven by the fact that all trainers, coaches and athletes are exploring ways to improve that parameter [10].

Sprinting velocity for short distances is an important element of performance in team handball. Players are required to cover distances between 20-30 m with maximal speed from the phase of attack to the phase of defense after a ball loss, or in order to prevent a fast break. Male and female players of the present study show similar values at the speed test in comparison with Israeli elite and sub-elite players of the same age [11]. Compared to NSP, male SP were significantly faster over 30-m sprint running. However, differences in sprinting ability between NSP and SP were not significant in female players. Female team handball is less popular in Greece and at a significantly lower level than male team handball. As a result, trainer's choices are to be made by a smaller sample compared to males. This probably explains the non-existence of many important differences between female players. 
This finding proves the importance of sprinting speed in handball. Differences were especially pronounced in wings. Results from female SP have shown that wings are the fastest players of the team while they develop instant fast break covering the largest field space [7]. In these fast break movements, first meters are important as high speed is an advantage to re-bounds and contributes to shoots success percentage after fast break. Researchers who have compared elite to sub-elite players or elite to amateur handball players have reported differences in sprinting ability. Lidor et al. [11], testing for the selection of male and female young players, report significant differences in 20 -m sprint in the final phases of a two years selection schedule. In addition, compared to second division, first division female players were significantly faster over 5- and 15-m sprint running [9].

Standing long jump is a reliable test for evaluating the ability to achieve high muscular force very rapidly which is of great importance in team handball. SP and NSP male and female players exhibit similar values in standing long jump compared to Israeli elite and sub-elite players of a similar age [11]. The present study reported that standing long jump was significantly lower in NSP male and female players. An interesting finding was that no significant differences were found between SP and NSP when their playing position was taken into account. In any case, SP wings, backs and pivots show a non significant superiority in relation to their NSP peers. Only male NSP goalkeepers were superior in standing long jump compared to their SP peers. Regarding standing long jump, our results are in agreement with a previous study that mentioned mean values of 215 and $190 \mathrm{~cm}$ for elite male and female and 204 and 165 for sub-elite male and female respectively [11].

Maximal oxygen uptake seems to be an important factor which distinguishes young players according to their level. Depending on the level of competition and the position in the team, handball players usually cover a distance between 4.5$6.5 \mathrm{~km}$ and require high levels of aerobic capacity to aid recovery after high-intensity bouts of activity [6, 21, 23]. The mean $\mathrm{VO}_{2 \max }$ for SP was 51.93 and $49.73 \mathrm{ml} \cdot \mathrm{kg}^{-1} \cdot \mathrm{min}^{-1}$ for males and females respectively, values similar to others reported in the literature $[6,24]$. One must record the statistically significant superiority of SP wings, as during the game they are the ones performing most of the fast breaks, covering a highly significant greater total distance [25]. The player during the game should maintain the potential of the optimal output in ball velocity and accuracy in shooting and reported data refer that throwing effectiveness is significantly affected by time, as aiming accuracy gradually decreases [21]. In this stage, it is important to develop an aerobic base in younger players, as this helps to delay the onset of fatigue during training as well as during competition, contributing in simultaneous development of skills.

Results of the present study show that SP players in whole (mainly males), achieved higher scores in most physical tests compared to NSP players. Several studies provide data regarding physical fitness and anthropometric characteristics of young players in various sports, in an effort to identify talents (for a review see Williams \& Reilly [17] and Pearson et al. [19]). Elite 16yrs soccer players achieved a better performance than sub-elite players in sprinting, agility, vertical jumping, aerobic power and body composition, as well as in technical and psychological skills [26, 27]. In field hockey, elite young players performed better than sub-elite in sprinting performance, repeated shuttle sprint performance and 20-m shuttle run test [28]. Endurance, flexibility, speed, and medicine ball throwing, showed a significant correlation with game proficiency in young female volleyball players' performance [29]. Gabbet et al. [30], suggest that anthropometric and physical fitness characteristics should be included in any testing procedure for young volleyball players, providing objective information on the players' progress during a competition season. Performance capability may be in some cases restricted by an insufficient physical fitness status [30]. These findings suggest that physical fitness measures could aid in the selection of players for team sports. On the other hand, it has been reported that tactics, motivation and technical skills play a far more important role in elite-level team sports than physical and physiological characteristics. Moreover, in older players, the small variability in physical fitness makes the identification of the talented players difficult to be achieved only by anthropometric and physical characteristics [19, 29]. It seems that different tests and abilities should be evaluated in different ages in order to have the more reliable results in talent identification.

\section{CONCLUSION}

The present study examined the effectiveness of a battery of motor tests for distinguishing SP from NSP young handball players, and concluded that there is a wide overlap between SP and NSP players. Specific anthropometric and physical characteristics distinguished mainly the male SP players. Stature, arm span, ball velocity, maximal oxygen uptake and running speed seem to be the most important components for selecting a talented young player. These findings suggest that physical and anthropometric characteristics should be included in any selection testing of junior handball players. However, the selection should not be restricted to anthropometry, especially in young ages where maturation is involved. However, the measurement of additional physical characteristics (e.g. agility), in combination with specific handball game tests (e.g. aiming accuracy, passing, dribbling in slalom) should also be included in a selection procedure. The ability to move with the ball, the ability to change directions rapidly, the ability to aim accurately at the goal, the ability to move around a triangle scheme (defence movement) are very important parameters and should be taken into account when testing handball players. The evolution of standard tests that simulate the game's circumstances along with the evaluation of specific physical fitness abilities and anthropometric characteristics are crucial for the future of team handball. The obvious challenge for trainers is to develop a specific skill and physical fitness test in combination with anthropometric characteristics making it possible to accurately measure the wide range of skills and requirements of different playing positions.

\section{REFERENCES}

[1] Delamarce P, Gratas A, Beillot J, Dassonville J, Rochcongar P, Lessard Y. Extent of lactic anaerobic metabolism in handballers. Int J Sports Med 1987; 8: 55-9.

[2] Sibila M. Initial and further selection of children gifted for handball on the basis of some chosen morphological and motor parameters. Handball EHF Periodical 1997; 1: 7-17. 
[3] Srhoj V, Marinović M, Rogulj N. Position specific morphological characteristics of top-level male handball players. Coll Antropol 2002; 1: 219-27.

[4] Skoufas D, Kotzamanidis C, Hatzikotoylas K, Bebetsos G, Patikas D. The relationship between the anthropometric variables and throwing performance in handball. J Hum Mov Sci 2003; 45: 46984.

[5] Fleising G, Barrentine S, Zheng N, Escamilla R, Andrews J. Kinematic and kinetic comparison of baseball pitching among various level of development. J Biomech 1999; 32: 1371-5.

[6] Kotzamanidis C, Chatzokotoulas K, Giannakos A. Optimisation of the training plan of the handball game. Handball EHF Periodical 1999; 2: 49-55.

[7] Rogulj N, Srhoj V, Nazor M, Srhoj L, Čavala M. Some anthropologic characteristicsof elite female handball players at different playing positions. Coll Antropol 2005; 29(2): 705-9.

[8] Gorostiaga EM, Granados C, Ibáñez J, Izquierdo M. Differences in physical fitness and throwing velocity among elite and amateur male handball players. Int J Sports Med 2004; 25: 1-8.

[9] Granados C, Izquierdo M, Ibáñez J, Bonnabau H, Gorostiaga EM. Differences in physical fitness and throwing velocity among elite and amateur female handball players. Int J Sports Med 2007; 28: 860-7.

[10] Hoff J, Almåsbakk B. The effects of maximum strength training on throwing velocity and muscle strength in female team-handball players. J Strength Cond Res 1995; 9(4): 255-8.

[11] Lidor R, Falk B, Arnon M, Cohen Y, Segal G, Lander Y. Measurement of talent in team handball: the questionable use of motor and physical tests. J Strength Cond Res 2005; 19 (2): 318-25.

[12] Léger LA, Mercier D, Gadoury C, Lambert J. The multistage 20 metre shuttle run test for aerobic fitness. J Sports Sci 1988; 6(2): 93-101.

[13] Ibnziaten A, Poblador MS, Leiva A, et al. Body composition in 10 to 14-year-old handball players. Eur J Anat 2002; 6(3): 153-60.

[14] Hatzimanouil D, Oxizoglou N. Evaluation of the morphological characteristics and motor skills in the national junior handball teams of Greece and Yugoslavia. J Hum Mov Stud 2004; 46: 12540.

[15] Burton AW, Greer NL, Wiese DM. Changes in overhand throwing patterns as a function of ball size. Pediatr Exerc Sci 1992; 4: 50-67.

[16] Bayios IA, Bergeles NK, Apostolidis NG, Noutsos KS, Koskolou MD. Anthropometric, body composition and somatotype differences of Greek elite female basketball, volleyball and handball players. J Sports Med Phys Fitness 2006; 46: 271-80.

[17] Williams AM, Reilly T. Talent identification and development in soccer. J Sports Sci 2000; 18: 657-67.
[18] Reilly T, Bangsbo J, Francs A. Anthropometric and physiological predispositions for elite soccer. J Sports Sci 2000; 18: 669-83.

[19] Pearson DT, Naughton GA, Torode M. Predictability of physiological testing and the role of maturation in talent identification for adolescent team sports. J Sci Med Sports 2006; 9: 277-87.

[20] Gorostiaga E, Izquierdo M. Effects of heavy resistance training on maximal and explosive force production, endurance and serum hormones in adolescent handball players. Eur J Appl Physiol 1999; 80: 485-93.

[21] Zapartidis I, Gouvali M, Bayios I, Boudolos K. Throwing effectiveness and rotational strength of the shoulder in team handball. J Sports Med Phys Fitness 2007; 47: 169-78.

[22] Bayios IA, Anastasopoulou EM, Sioudris DS, Boudolos KD. Relationship between isokinetic strength of the internal and external shoulder rotators and ball velocity in team handball. J Sports Med Phys Fitness 2001; 41: 229-35.

[23] Perš J, Bon M, Kovačič S, Šibila M, Dežman B. Observation and analysis of large-scale human motion. Hum Mov Sci 2002; 21: 295-311.

[24] Jensen K, Johansen L. Physical performance measured during running, sprinting, jumping and throwing in three national handball teams. Scand J Med Sci Sports 1994; 4: 265-6.

[25] Luig P, Manchado-Lopez C, Perš J, et al. Motion characteristics according to playing position in international men's team handball. In: Cabri J, Alves F, Araújo D, Barreiros J, Diniz J, Veloso A, Eds. Proceedings of the 13th Annual Congress of the European College of Sport Science; Faculdade de Motricidade Humana, Universidade Técnica de Lisboa: Portugal 2008.

[26] Reilly T, Williams A, Nevill A, Franks A. A multidisciplinary approach to talent identification in soccer. J Sports Sci 2000; 18: 695-702.

[27] Janssens M, Van Renterghem B, Bourgois J, Vrijens J. Physical fitness and specific motor performance of young soccer players aged 11-12 years. J Sports Sci 2000; 16: 434-5.

[28] Elferink-Gemser M, Visscher C, Lemmink K, Mulder T. Relation between multidimensional performance characteristics and level of performance in talented youth field hockey players. J Sports Sci 2004; 22: 1053-63.

[29] Stamm R, Veldre G, Stamm M, et al. Dependence of young female volleyballers' performance on their body build, physical abilities, and psycho-physiological properties. J Sports Med Phys Fitness 2003; 43: 291-9.

[30] Gabbett T, Georgieff B, Domrow N. The use of physiological, anthropometric, and skill data to predict selection in a talentidentified junior volleyball squad. J Sports Sci 2007; 25(12): $1337-$ 44 . 